\title{
RELACIÓN, INTERACCIÓN E \\ IMPLICACIÓN ENTRE LA \\ FILOSOFÍA Y LA EDUCACIÓN
}

Enma Pazmiño A., fma

\section{Introducción}

El fenómeno educativo, tratado por la pedagogía, no está ligado estrictamente a la significación etimológica griega: paidós $=$ niño, y agein $=$ dirigir, llevar... sino más bien desde otra connotación, la de desarrollar, provocar, respetar, como lo afirma Rousseau, en su libro "Emilio o la educación", educar es respetar y favorecer en el niño sus tendencias naturales, preparar situaciones libres para su natural desarrollo. ${ }^{1}$

En todas las épocas, la educación siempre ha apuntado a los grandes ideales para ser alcanzados y perfeccionados, así como también ha formulado procesos formativos orientados a la eficacia; y lo ha hecho merced a la filosofía, puesto que por su naturaleza, es la determinante en lo que debe ser la educación, en los ideales, los valores que la educación debe proponerse. Además, el ser humano, como tal, ha sentido la necesidad de tener prin- 
cipios para guiarse y guiar a los demás, ha sentido la necesidad de relacionarse implícita o explícitamente con un sistema filosófico que le permita diseñar su vida con más acierto, tomar decisiones, dar juicios de valor, conducirse hacia el "buen vivir", hacia la felicidad.

Esta preocupación de la persona humana por la educación se fundamenta en su misma naturaleza, y como fenómeno constante ha sido la garantía más segura de dar continuidad a la civilización y a la cultura de los pueblos y no sólo para preservarla y perpetuarla, sino además, desde el enfoque filosófico, para criticarla y evaluarla para beneficio de las nuevas generaciones; por ello la educación justifica su razón de ser, es decir logra su cometido sólo a partir de la reflexión crítica, de la presencia de la filosofía, de su interacción e implicación con ella, dejando de lado las no menos importantes reflexiones científicas y técnicas que engloban la educación; por eso la temática propuesta se desglosa en estas reflexiones:

\section{Relaciones entre filosofía y educación}

La educación, como vocación-misión, obligatoriamente lleva a interrogarse por el cómo mejorar el trabajo educativo en la clase, en el aula; qué nuevos modelos buscar y aplicar; qué otras alternativas se pueden optar a fin de renovar, revitalizar, promover una mayor calidad en el proceso de aprendizaje y responder de modo eficiente y eficaz a las exigencias de la persona con las demandas del entorno, de la cotidianidad.

Se trata de salir de un status quo y dar paso al cambio, a la acción, al dinamismo, se diría al estilo socrático, es decir, a hacer filosofía desde la posición de Sócrates, modelo de maestro con quien los discípulos logran llegar al aprendizaje, al conocimiento desde la relación dialéctica; a cambiar las maneras de pensar inicial, de 
sentir, de accionar; es decir, hacer filosofía en la educación con el modelo socrático.

En Sócrates, la filosofía no es adquisición de conocimientos, no es aprenderla a partir de un esquema formal, es más bien una forma de vida, es tomarla como una práctica con múltiples aplicaciones, pero sobre todo es hacerla, realizarla. Para Sócrates, la filosofía es praxis; por eso Sócrates representa al auténtico filósofo-maestro que ejercita su pensamiento ligado a la praxis. El pensar, el saber, en otras palabras el filosofar, es para Sócrates diálogo, dinamismo, acción, praxis. Pero, ¿acaso es posible hacer filosofía en el aula, en el proceso de aprendizaje? ¿Es o no compatible la filosofía con los intereses de los niños, de las niñas, de los adolescentes? Pues, basta recordar por ejemplo, en los primeros diálogos de Platón, cómo Sócrates filosofa tanto con niños, con jóvenes, como con mayores. Los personajes que aparecen en el diálogo de LISIS por ejemplo, se dice que son chicos de once años y Sócrates no tiene ningún reparo en filosofar con esos niños, de problematizar lo que está delante, que muchas veces, en la cotidianidad, del día a día, se dan como sabidas, como sentado; es decir, Sócrates, desde su perspectiva filosófica y de maestro, busca el saber y el ser asimilado entre todos. Es más, su afán metodológico, no es saber cómo son las cosas, sino más bien que las cosas tengan una utilidad para un servicio humano, un sentido de humanización. A Sócrates le mueve sobre todo la justicia y la verdad; no le interesan ni el dinero, ni los cargos públicos ni el poder, sólo quiere que se ejerza bien. ${ }^{2}$

El concepto de filosofía en Sócrates es muy claro, para él la teoría se convierte en praxis, en fuerza política, en un despertar de conciencias; por eso, esa actitud socrática es percibida por los atenienses como peligrosa, la de "corromper a la juventud," lo que luego le 
mereció la condena a muerte. En este sentido, la filosofía deviene para él, una vida filosófica, porque es una forma de vida entregada a la re-creación del ámbito educativo, a la transformación de la realidad, a ponerse en el compromiso de captar el entorno, de vivir el encuentro, de sentir la complementariedad, asumiendo cada quien los roles de "no sólo a educar, sino sobre todo a educarse" en el continuo y mutuo crecimiento. ${ }^{3}$

La radicalidad de Sócrates es tal que se olvida de sí mismo y aún de los suyos para dedicarse exclusivamente al bien de los demás lo que testimonia su vida de pobreza y su muerte.

Según el pensamiento de Ignacio Ellacuría, Sócrates, dentro de los filósofos griegos, es un claro y buen ejemplo, porque en él la filosofía no es una contemplación cerrada en sí misma, sino que deviene acción educativa y por ende en acción política; además, Sócrates tiene presente que la búsqueda de la verdad, del conocimiento que facilita y es propio de la filosofía no puede degenerar en la inacción, en el conformismo de los sofistas o en la incoherencia entre la teoría y la práctica. Sócrates logra relacionar, interactuar entre los dos ámbitos: filosofíaeducación y desarrollar el pensamiento, ejercitar la reflexión capaz de transformar la realidad haciéndola más humana, virtuosa y justa, porque el pensamiento y la reflexión socrática surgen de la realidad y retornan hacia ella transformándola en una nueva realidad. ${ }^{4}$

Así pues, en esta óptica, la filosofía consiste en la búsqueda de sentido de la vida; por esto, cabe pensar y preguntarse, por ejemplo: ¿qué sentido tiene para los niños, las niñas, los y las jóvenes aquello que estudian, investigan, realizan tareas, trabajan, hacen cosas?, y los adultos, ;piensan quizá el para qué de su existencia en este mundo, el sentido que las cosas tienen en sus vidas?, o 
¿resulta más cómodo o se vive mejor cuanto menos se piensa? Por otra parte, tampoco se puede desestimar, en el área escuela, el valor de las ciencias naturales, las matemáticas, la química, la historia, etc., porque dentro de este mismo contexto dialéctico maestro-discípulo, surge el conocimiento, el aprendizaje de habilidades, la asimilación de valores, de actitudes, en suma, el saber, los saberes y su aplicación, lo que en la misma línea, Jacques Delors afirma cuando dice que la educación - reflexiva-filosófica- lleva a cada persona a despertar, a descubrir e incrementar sus posibilidades creativas. De ahí los cuatro pilares de la educación que Delors propone:

- Aprender a conocer, que implica aprender a aprender, vale decir aprovechar las posibilidades que ofrece la educación a lo largo de la vida.

- Aprender a hacer, esto es adquirir cualificación, competencia.

- Aprender a vivir juntos a convivir es decir vivir la unidad, la identidad personal con los valores de la pluralidad.

- Aprender a ser, lograr la capacidad de autonomía y responsabilidad personal. ${ }^{5}$

La filosofía, entonces, de acuerdo al modelo socrático, mueve a la propia reflexión y al razonamiento de los alumnos, provoca al foro, al autoconocimiento, a descubrir por sí mismos, la relevancia o no que tiene para sus vidas aquello que hacen o dejan de hacer; por eso, las habilidades de razonamiento que maneja la filosofía son instrumentos esenciales que contribuyen al aprendizaje significativo en todos los ámbitos y de modo efectivo, vale decir de manera eficiente y eficaz especialmente en el ámbito de las ciencias, por ejemplo en el área de mate- 
máticas, en el área de lenguaje en cuanto a la lectura comprensiva, a saber escribir bien, a saber expresarse con lógica y fluidez.

Este es el objetivo de la educación y de la filosofía en su relación e interacción: llenar las expectativas, aprender a pensar, eliminar la ignorancia, lograr la autonomía de la razón, salir de la minoría de edad por su propio entendimiento, entrar a investigar, a inspeccionar, atar cabos sueltos, ponderar, deliberar, calcular, arriesgarse, detectar relaciones, conocer, reconocer, saber interpretar, tener ideas claras para poder criticar, o como apunta Edgar Morin en Los siete saberes para la educación del futuro: tener la capacidad de curar las cegueras del conocimiento esto es, el error, la ilusión; garantizar el conocimiento pertinente; conocer al ser humano situado en el universo; conocer la identidad terrenal, es decir la pertenencia a la tierra, a la casa común, a la última y primera patria; enfrentar las incertidumbres, no sólo sobre el futuro, sino también sobre la validez de los conocimientos; lograr la comprensión, la convivencia democrática, planetaria; conocer la ética del género humano, esto es, el respeto a la persona, a la sociedad porque pertenecen a la única especie, la humana. ${ }^{6}$

Esto es, entonces, hacer y vivir el dinamismo del espíritu filosófico en la educación donde no hay cabida para la información propiciada sólo de un lado, que se vuelve acrítica e indigesta; porque si bien la filosofía de la educación, como reflexión, es también un saber teórico, no está en las nubes, sino bien asentado en el suelo, es que es un saber crítico entremezclado con la realidad y de ella cobra su sentido. Es más, en el pensamiento de Paulo Freire, el saber educativo es como una terapia contra el fanatismo educativo esclavizante. Es una terapia, porque como Sócrates, Freire facilita el diálogo, como método, a 
fin de transformar aquello que está identificado como la causa opresora y de la insatisfacción para lograr una educación auténticamente liberadora. ${ }^{7}$

Así pues, lo que eleva al ser humano por encima de todos los seres vivos es la capacidad o la facultad del pensamiento, del conocimiento, pero sobre todo la capacidad de actuar reflexiva e intelectualmente, como anota Giordano Bruno, cuando dice que la Providencia ha determinado que el hombre esté ocupado en la acción por las manos y en la contemplación por el intelecto; en otras palabras, que no se dé la contemplación sin la acción, ni la acción sin la contemplación, lo cual lleva de la mano a subrayar aún más la interacción e implicación de la filosofía y la educación.

\section{Interacción e implicación entre filosofía y educación}

Ante todo conviene precisar brevemente la significación de interacción e implicación. La interacción es más bien un fenómeno externo, visible y hace referencia a un actuar simétricamente entre dos, es un intercambio de acciones, procesos, situaciones, generalmente en condiciones de equidad, de igual a igual.

La implicación, etimológicamente proviene del latín: “in-plicare," significa lo que está "plegado", doblado, oculto, lo que está dentro, no visible o perceptible y a veces necesita ser desdoblado, explicado, descubierto. Entonces, todo lo que rodea no es un conjunto de cosas, de hechos, de situaciones aisladas, colocadas al "azar" sino más bien como un proceso, como un conjunto, como un todo de cosas, de hechos, de situaciones relacionadas entre sí, de forma que unos "dependen" de otros, unos hechos "suceden" a otros. En otras palabras, se da por sentado que unas cosas implican otras y los hechos también se implican unos en otros. 
Sin embargo, vale insistir que la implicación de las cosas, de los hechos no es que se den o se sucedan de forma arbitraria, sino conforme a una lógica, a unas reglas, a unas leyes; por ello, el conocimiento, la ciencia, que es producto de la interacción e implicación entre la reflexión filosófica del sujeto y la realidad, supone también una depuración del conocimiento vulgar que está implicado, a fin de lograr lo mejor posible la nitidez del conocimiento científico, que por otra parte, la implicación tiene en sí, un contenido o relación semántica, de significación, clara, comprensiva y verdadera.

En las reflexiones arriba propuestas sobre las relaciones entre filosofía y educación, de alguna manera explícita o implícita, se ha hecho referencia al fenómeno de la interacción e implicación de filosofía y educación, indicando que detrás o debajo de cada una de ellas está inseparablemente el pensamiento y la acción, es decir la filosofía y la educación caminan indefectiblemente juntas; por eso para algunos filósofos y educadores como Sócrates, Platón, Kant, Herder, John Dewey, no existe filosofía que no busque desentrañar el sentido de la vida, tener una visión unitaria de lo real y compartirla; como no existe pedagogía ni educación que no se asienta en una determinada cosmovisión y en un determinado contexto histórico concreto, por tanto, no es posible pensar una filosofía sin Pedagogía, sin educación o una educación que no dé cara a la filosofía; es decir, existe mutua dependencia y las dos justifican su razón de ser porque ambas convergen en el tema central que es la persona humana, y por ello interactúan y trabajan en el problema antropológico y la filosofía se pregunta intentado resolver: ¿Qué es el hombre? ¿Qué es el conocimiento? ¿Qué puede conocer el hombre? ¿Qué es el saber? ¿Qué puede hacer? ¿Qué puede esperar?, y la educación, a su vez, vuelca su 
interés y preocupación de ¿cómo lograr el conocimiento, el saber, la formación, el cultivo de valores en la persona, en este sujeto concreto de carne y hueso que está delante, que nace, sufre, muere, como dice Miguel de Unamuno?; y la respuesta es simple y obvia: sólo desde el ejercicio del pensamiento en interacción con la realidad surge la persona humana en su orquestación armónica con su yo y con el mundo.

Por eso al hablar de interacción e implicación entre filosofía y educación viene al caso hacer referencia también a las posiciones de John Dewey, de Jean Piaget, de Carl Rogers para quienes la educación es filosofía pragmática (Dewey), que el proceso educativo, el conocimiento, se enriquece en la interacción natural de los educandos con el entorno, con el medio ambiente, en otras palabras, la educación es el movimiento dialéctico, la acción intencionada del sujeto por conocer, por saber más de los objetos que le rodean, de los hechos, situaciones de su entorno. En todo caso, tanto John Dewey, como Jean Piaget, así como Carl Rogers, cada uno con su matiz propio, convergen en hacer evidente la inseparable correlación activa y permanente del pensar y del actuar en la adquisición del conocimiento. Para John Dewey, por ejemplo, en referencia a la filosofía pragmática, la meta educativa es lograr el más alto nivel o etapa de desarrollo, lo que se obtiene en la interacción de sujeto - ambiente, en donde en realidad aprende haciendo; del otro lado, la teoría de Jean Piaget fomenta el desarrollo de la inteligencia a través de la interacción con los materiales educativos y la acción transformadora del sujeto, es decir, el sujeto, al interactuar con el ambiente físico, social, construye y reconstruye la realidad, por eso para Piaget el conocimiento es un fenómeno construido mediante la interacción del sujeto con el ambiente físico, social; en 
suma, conocer para Piaget es actuar física e intelectualmente sobre las cosas, las imágenes, los sonidos. ${ }^{8}$ En la misma línea, Rogers enfatiza que el sujeto construye su conocimiento a través de la interacción con el medio que le circunda y, por el conocimiento que el sujeto realiza con el mundo circundante, logra una modificación de su conducta y una mayor autonomía intelectual y social. 9

Entonces, entre el sujeto cognoscente (alumnos, guías, maestros) y el objeto de conocimiento que no sólo es un objeto físico animado o inanimado sino también, hechos, situaciones, otros sujetos, entes, abstracciones, conceptos, formas de pensamiento, etc., se da una suerte de relación, de interacción, e implicación mutua; es decir, por una parte, en el proceso de aprendizaje, entra la aprehensión que hace el sujeto del objeto, y en este sentido, el sujeto se transforma, se ve influenciado por las características del objeto, vale decir que el objeto determina al sujeto a través de la experiencia "única" que tiene el sujeto; por ejemplo, un libro, una película, un ser o ente de la naturaleza, o lo que sea, como objetos de conocimiento, transforman la conciencia del sujeto, en cuanto éste, de manera intencionada, los aprehende; de modo que mientras el sujeto cognoscente, por la experiencia "única” que tiene en el juego dialéctico de ida y vuelta -sujeto-objeto-, le da también una significación al objeto, sin embargo el objeto queda intacto en su esencia, en tanto que el sujeto, en este caso, queda cambiado en cuanto a su estado original de conciencia.

Así pues, la información que el sujeto obtiene, del objeto, según la "clásica" relación, de: $S \leftarrow \rightarrow O$, pero aquí, considerada como dinámica y simétrica, en ese proceso intencionado del sujeto por conocer, es lo que da por resultado el conocimiento, y luego por una lógica ordenada, organizada y sistematizada, se convierte en un saber, 
o en un nuevo saber; un saber que viene a ser un conjunto de conocimientos en torno al tema, al objeto de conocimiento, que ayudan a su vez a explicar otros procesos o situaciones nuevas de aprendizaje.

El conocimiento entonces, construido por el que conoce (sujeto) es activo, porque vale reiterar que conocer es actuar, manipular, operar, pensar. El pensamiento consiste en la acción, en una actividad intelectual que mueve todo el ser de la persona en interacción con la realidad y mutua construcción, y el sujeto construye la realidad, en la medida que se construye a sí mismo. Así se confirma un proverbio que dice: "nadie enseña lo que sabe, sino lo que es" o parafraseando alguna frase célebre, el conocimiento interactivo es como la abeja que recoge el néctar de flor en flor, elabora la miel en beneficio de todos y es que el conocimiento adquirido en mutua construcción tiene que ser también compartido, porque cuanto más se comparte, más se enriquece.

\section{Reflexiones finales:}

Para terminar, cabe puntualizar algunas consideraciones hechas a lo largo del artículo y resaltar, de manera proactiva e inequívoca, la importancia de la relación, interacción e implicación entre la filosofía y educación.

Del análisis realizado se puede afirmar, sin más, que la educación no puede existir sin la filosofía, como la filosofía, desde su rol específico, no puede ser tal si no se concreta o se expresa en una realidad como es en el caso de la educación.

La filosofía desde su función reflexiva y dialéctica, lleva indefectiblemente al cuestionamiento de la realidad, a poner en duda las situaciones dadas y por ello a desentrañarlas y darles el sentido, el movimiento, el valor 
comunitario y lograr la capacidad de asombro ante las cosas que la vida y la realidad cotidiana presentan.

El objetivo de la filosofía con la educación es lograr el conocimiento incluso desde una situación afectiva, empática de interacción y relación entre la luz y la realidad; en otras palabras, entre el maestro que no es la persona que sabe más y los discípulos que son los que no saben nada, sino un encuentro simétrico, en una actitud socrática nueva.

Lo significativo en este juego dialéctico del aprendizaje, sujeto - realidad, es el hecho de que lo aprehendido de las distintas informaciones, deviene luego en producto o conocimiento totalmente nuevo, fruto exclusivo y propio del sujeto.

Así pues, con esto, en la educación, en sintonía con la filosofía, se pretende lograr personas autónomas, responsables, críticas, capaces de pensar por sí mismas, de autocrítica, de autoevaluación y capaces de tomar sus propias decisiones.

En todo caso, estas consideraciones aquí expresadas podrían ser una invitación para quienes quieran reflexionar sobre la importancia y necesidad de hacer de la educación en interacción con la filosofía, la verdadera escuela de formación integral de maestros y discípulos. 


\section{Notas}

1 Incola Abbagnano. Diccionario de Filosofía, México, F.C.E., 1981.

2 PLATÓN. Diálogos, Madrid, Gredos, 1981.

3 LOME, Madrid. Editorial CCS, 2005.

4 Hector, Samour, Voluntad de liberación. La filosofía de Ignacio Ellacuría, Granada, 2003.

5 DELORS, Jaques. La educación encierra un tesoro, Madrid, Ediciones UNESCO 1006.

6 MORIN ,Edgar. Los siete saberes para la educación del futuro.

7 Paulo FREIRE. La pedagogía del oprimido, Buenos Aires, Editorial Siglo XXI, 1985.

8 Jean, Piaget. Aportes a la teoría del conocimiento, 1996.

9 Carl, Rogers. La persona como centro, Barcelona, Herder, 1981. 


\section{Bibliografía:}

\section{ABBAGNANO}

1981 Incola, Diccionario de Filosofía, México, F.C.E.

DELORS, Jaques

1996 La educación encierra un tesoro, Madrid, Editorial Santillana. Ediciones UNESCO.

FREIRE, Paulo

I24 2005 fma, Madrid, Editorial CCS.

Pedagogía del oprimido, Buenos Aires, Editorial Siglo XXI.

MORIN, Edgar

PIAGET, Jean

UNESCO, Los siete saberes para la educación del futuro.

1996 Aportes a la teoría del conocimiento, .

PLATON, Diálogos,

1981 Introd. Emilio Lledó Iñigo, Madrid, Gredo,. ROGERS, Carl

1981 La persona como centro, Barcelona, Herder.

SAMOUR, Hector

2003 Voluntad de liberación. La filosofía de Ignacio Ellacuría, Granada. 